\title{
O CBCE COMO "SOLO COMUM" PARA DIÁLOGOS NECESSÁRIOS AO CAMPO DA EDUCAÇÃO FÍSICA
}

\section{QUATRO APONTAMENTOS INTRODUTÓRIOS...*}

\author{
MS. RICARDO REZER \\ Professor da Unochapecó \\ Doutorando em educação física da Universidade Federal de Santa Catarina (PPGEF/UFSC) \\ Líder do Grupo de Pesquisas Pedagógicas em Educação Física (GPPEF) (Santa Catarina - Brasil) \\ E-mail:rrezer@hotmail.com
}

\begin{abstract}
RESUMO
Este texto tem por objetivo central problematizar o papel do Colégio Brasileiro de Ciências do Esporte (CBCE). Para tal, inicialmente apresento um resgate das perspectivas de fundo que se construíram no $C B C E$, para, em um segundo momento, apresentar quatro apontamentos sobre problemáticas inerentes ao entorno do CBCE. Finalmente, no quarto apontamento, apresento algumas posições acerca de possibilidades comunicativas importantes para um cenário como o do CBCE, pensando-o como um "solo comum" para diferentes comunidades que se relacionam direta ou tangencialmente com o campo da educação física.
\end{abstract}

PALAVRAS-CHAVE: CBCE; solo comum; educação física.

* Este texto deriva-se de uma intervenção na abertura do Pré-Conbrace CDS/Nepef/UFSC, realizado em Florianópolis (SC), em setembro de 2009. Trata-se de um texto pessoal, que não representa necessariamente a posição de nenhum coletivo. O presente trabalho não contou com apoio financeiro de nenhuma natureza para sua realização. Não houve conflitos de interesses para realização do presente estudo. 
Ao iniciar este texto, lembro uma frase de Heidegger, em que ele afirma que a angústia é a compreensão da precariedade da condição humana. Em certa medida, essa afirmação, por um lado, contribui para lidar com a angústia que apresento neste início, no sentido de escolher "por onde começar a lida", e, por outro, tranquiliza esse esforço inicial, na medida em que expressa, ao mesmo tempo, a impossibilidade de apresentar argumentos definitivos acerca do tema proposto, bem como evidencia a responsabilidade necessária para transitar por caminhos não tranquilos de um campo do conhecimento ainda recente, tal como a educação física (EF) brasileira.

Dessa forma, sem ter a pretensão de resolver os problemas que doravante serão apresentados, mas sem abandonar a disposição e a responsabilidades de enfrentá-los e compreendê-los melhor, entendo ser condição importante, para um maior balizamento dos contornos a serem estabelecidos neste texto, iniciar esse desafio partindo de uma questão de fundo: Como avançar no processo de construção de uma sociedade científica como o Colégio Brasileiro de Ciências do Esporte (CBCE), que supere a perspectiva de, por um lado, cair na tentação presunçosa de apresentar a "última palavra" sobre o campo da EF e, por outro lado, ficar sujeito à diversidade interpretativa que se apresenta na contemporaneidade desse campo? É possível perceber que, em meio a esses extremos, movimentos se vêm constituindo, a fim de enfrentar os desafios que essa questão apresenta.

Partindo dessa questão inicial, este texto tem por objetivo central problematizar o papel do CBCE, no sentido de estabelecer uma discussão que permita avançar na perspectiva de considerar essa sociedade científica como um cenário acadêmico-científico pautado pelo rigor e pela possibilidade de lidar com as diferenças, sem desconsiderar, em absoluto, as dificuldades que essa empreitada sugere, visto a constituição histórica de diferenças marcantes no próprio interior da EF brasileira.

Para tanto, inicialmente apresento um resgate das perspectivas de fundo que se construíram no CBCE, para, em um segundo momento, apresentar quatro apontamentos sobre problemáticas inerentes ao entorno do CBCE. No quarto apontamento, apresento algumas posições acerca de possibilidades comunicativas importantes para um cenário como o do CBCE, pensando-o como um "solo comum" para diferentes comunidades que se relacionam direta ou tangencialmente com o campo da EF. 


\section{O CBCE COMO LÓCUS PRIVILEGIADO PARA O DIÁLOGO NO ÂMBITO DA EF BRASILEIRA: PONTOS DE PARTIDA...}

Inicialmente, cabe destacar, lembrando Bianchetti (2009), que o CBCE teve de lidar desde os seus primórdios com um amplo leque de frentes que se vieram mostrando irreconciliáveis. Então, a complexa conjuntura atual em que se edifica o CBCE, de certa forma, não é novidade. Na direção de enfrentar a questão inicial apresentada anteriormente, é interessante destacar o artigo $1^{\circ}$ de seu estatuto.

O COLÉGIO BRASILEIRO DE CIÊNCIAS DO ESPORTE, CBCE, fundado em 17 de setembro de 1978, é uma associação científica, de duração indeterminada, sem fins econômicos, autônoma e congregadora de profissionais e estudantes que possuem em comum o interesse pelo desenvolvimento dos estudos e pesquisas relacionadas à área acadêmica convencionalmente denominada Educação Física (CBCE, 2009).

Nesse sentido, se observarmos nesse recorte a expressão "congregadora", ela se apresenta como um indicativo importante a ser considerado. Principalmente se considerarmos também, neste início de argumentação, o artigo $2^{\circ}$, que trata dos objetivos do CBCE, conforme a seguir:

a. Promover e incrementar os estudos e pesquisas relacionadas à área acadêmica Educação Física; b. Veicular o conhecimento produzido na área da Educação Física por meio da publicação de periódicos, da promoção de reuniões científicas e outras iniciativas de distintas ordens; c. Manter intercâmbio com entidades nacionais e internacionais com interesses em áreas afins e de caráter similar; d. Posicionar-se em questões de Políticas referentes às áreas com as quais guarda relação de estudo e produção de conhecimento (idem).

Assim, é possível perceber que a dimensão política se trata de uma esfera importante nesta discussão, porém não a única e, portanto, uma dimensão que precisa saber de seu lugar na configuração de uma sociedade que se pretenda científica. Esses pontos de partida representam uma construção que, em tempos de comunidades "plurais" no interior do campo da EF, merece também maior consideração de seus protagonistas'. Ao que parece, no âmbito da produção acadêmico-científica, passos tem sido dados nessa direção. Porém as dificuldades

I. Procuro-me aproximar do entendimento de política de Hannah Arendt (2007), em que ela afirma que a política se baseia na pluralidade dos seres humanos, bem como trata da convivência entre os diferentes, em que os seres humanos se organizam politicamente para certas coisas em comum. Nesse sentido, a política permite organizar a diversidade absoluta de acordo com uma unidade relativa e em contrapartida às diferenças relativas. 
de tratar isso na esfera política vêm-se manifestando como um complexo desafio a ser enfrentado no interior dessa sociedade científica.

Considerando que há movimentos que vão ao encontro das preocupações deste texto, manifestos na constituição de propostas das recentes direções do CBCE, que, tanto em nível nacional como em algumas secretarias, passaram a empreender ações que, conforme Bracht (2009), pudessem atrair pesquisadores e lideranças que se afastaram do CBCE, na perspectiva de redimensionar a ideia construída de que o CBCE se tornou um espaço representativo de um determinado grupo ou segmento da EF, e não do campo como um todo. Não obstante, o autor chama a atenção para alguns possíveis riscos dessa posição, tais como a submissão às regras dominantes do campo científico maior, o que, sem dúvida, seria mais um elemento paradoxal na busca pela autonomia pretendida.

O desafio de construir espaços entre diferentes segmentos, hegemônicos ou não, no âmbito do CBCE, se apresenta com uma complexidade imensa, visto as diferenças (muitas vezes irreconciliáveis) tanto do ponto de vista político como do ponto de vista acadêmico científico. Entendo que o esforço aqui proposto se trata de uma responsabilidade hodierna em tempos de movimentos que se manifestam na direção de diminuir distâncias entre campos do conhecimento. Reforçando essa posição, é possível lembrar que diversos autores em suas obras se vêm manifestando concretamente sobre a necessidade de promovermos fissuras nos muros disciplinares construídos nas e entre as diferentes ciências. Mesmo que por caminhos diferentes, diversos autores, alguns clássicos, tais como Gérard Fourez ( 1995), Ilya Prigogine (1996), Edgar Morin (2005), Thomas Kuhn (2006), Henry Atlan (1992), entre outros, cada qual ao seu modo, vêm percebendo a impossibilidade de "continuarmos" sem perceber a necessidade de estabelecer nexos entre as diferenças, perceber as possíveis aproximações, promovendo a constituição de "solos comuns", em que seja possível sentar, conversar, discordar e chegar ou não a acordos, edificando possibilidades comunicativas necessárias e/ou possíveis. Nas palavras de Berticelli (2004),

[...] estou profundamente convencido de que os educadores precisam "sentar-se à mesa" para conversar com cientistas das ciências ditas hard (duras), pois é preciso desenvolver esta competência, tanto de uns quanto de outros, a de serem capazes de pensar processos complexos (p. 21).

[...], até porque as ciências precisam integrar-se mais nesse vasto cenário ecológico, no mais amplo sentido, assumindo não apenas o estreito viés do descobrir e ensinar "como fazer" mas, para perguntar-se, junto com todos, sobre o porquê fazer e para refletir sobre as consequências desse fazer e do deixar de fazer, sem, ainda assim, arredar um passo em relação ao rigor do fazer científico (p. 34). 
Nesse caminho, torna-se importante entender a necessidade de ampliar o entendimento acerca do papel do CBCE e suas relações, por um lado, internas, entre seus diferentes grupos e, por outro, com diferentes outros campos, no sentido amplo de perceber que problemas complexos necessitam dimensões complexas de compreensão. A seguir, procuro pontuar melhor algumas questões específicas, por meio de quatro apontamentos introdutórios, assumindo uma postura que se apresenta no sentido de não ter a pretensão de "dar a última palavra" ou "bater o martelo", mas sim procurar compreendê-las melhor e pontuar como me venho relacionando com elas.

\section{QUATRO APONTAMENTOS INTRODUTÓRIOS...}

\section{PRIMEIRO APONTAMENTO - TENCIONANDO A RELAÇÃO TEORIA E PRÁTICA NO ÂMBITO DO CBCE...}

Como exemplo inicial, é admissível destacar um possível abismo existente entre uma sociedade científica, tal como o CBCE, e significativo grupo de trabalhadores que atuam no campo da EF, ou mesmo, como comumente se ouve falar, nas "áreas afins". Este, em minha posição, parece ser um ponto nevrálgico na definição dos rumos dessa sociedade científica. Embora não possa desconsiderar-se a necessidade da presença de professores e pesquisadores experientes no âmbito do CBCE, não se pode desconsiderar a necessidade de aproximação de suas produções com os sujeitos que atuam no cotidiano do campo em diferentes contextos, pois estes também são, ao seu modo, artífices da EF brasileira.

Possíveis abismos entre a produção acadêmico-científica e os trabalhadores do campo da EF precisam ser tencionados, a fim de contribuir para que a produção de pesquisas no âmbito da EF se aproxime de forma mais concreta das demandas dos espaços de intervenção.

Discuto em outro texto (REZER, 2009) que, paradoxalmente, na conjuntura de uma política científica que prima pela produção do conhecimento, o que, de certo modo, tal e qual uma "corrida" vem ampliando a produção do campo (a um preço bem alto), em contrapartida, não tem dado conta de aproximar a produção acadêmica de significativa parcela de trabalhadores da EF. Venho percebendo que, se na sociedade de consumo o mais importante é o processo de comprar e nem tanto o que se compra, na lógica do publish or perish, da mesma forma, o mais importante não é estudar e discutir o já publicado, mas publicar, de novo, de novo... em um processo (obsessivo?) que parece não ter fim. 
A questão não se trata então de não mais publicar, mas de ampliar o número de autores, de leitores e que os textos tenham o que dizer, superando a publicação como mero capital acadêmico, mas que representem o esforço investigativo da área. Em tempos em que relatos de experiência são vistos com desconfiança por significativo número de periódicos, talvez essa dimensão editorial pudesse representar uma importante possibilidade de vincular as relações entre teoria e prática, por intermédio da escrita fundamentada de professores e professoras que operam no cotidiano do campo, em diferentes contextos. Lembro que significativo número de periódicos não aceitam a submissão de relatos de experiências.

Porém é preciso reconhecer que. no âmbito do CBCE, a Revista Brasileira de Ciências do Esporte (RBCE) vem veiculando textos nessa linha editorial (apenas para citar um, lembro o texto de Medelros, 2007). Nessa direção, a RBCE, disponível também on-line, se apresenta como um canal comunicativo importante para construir pontes entre o CBCE e outros contextos, como, por exemplo, a escola.

Não obstante, tenho realizado diversas intervenções junto a professores das redes públicas de diferentes cidades na região Sul do Brasil, principalmente Rio Grande do Sul e Santa Catarina, e venho percebendo o pequeno conhecimento sobre a RBCE ou mesmo sobre o CBCE, seu papel e as possibilidades de participação dos professores nesse contexto, frequentemente considerado espaço para intelectuais oriundos das universidades, e não para professores que operam no chão da quadra/sala de aula da escola, da academia, do clube, entre outros².

Concordando com as ideias apresentadas por Bianchetti (2009) no volume 30 da RBCE, entendo que o compromisso dos intelectuais não se trata de pouca coisa, entretanto é necessário perguntar de que forma o trabalho desenvolvido pelos intelectuais se afasta e/ou se aproxima dos trabalhadores do campo, sem, necessariamente, baratear e vulgarizar a possibilidade de produção do conhecimento no campo da EF, promovendo a possibilidade de esses próprios professores e professoras, ora distantes do CBCE, também se perceberem como intelectuais ${ }^{3}$.

2. Lembro de um encontro com professores e estudantes de São Miguel do Oeste (SC), em que um professor de EF escolar afirmou que não sabia que gente como ele poderia fazer parte do CBCE.

3. Na direção de enfrentar essa preocupação, percebe-se uma motivação crescente para a escolha de temas de eventos e periódicos científicos, representando a perspectiva de que pesquisadores da EF se vêm dando conta de que "apenas" pesquisar e publicar não basta. É necessário discutir e refletir o que se produz, "para quem" e "para que" se pesquisa e publica (Para contribuir com o movimento de avançar com o desenvolvimento do campo, pelo enfrentamento de suas demandas ou para "contabilizar" capital acadêmico no Currículo Lattes?). Para ficar apenas em alguns exemplos de como segmentos da EF se vem preocupando em discutir as relações (ainda não resolvidas) entre teoria e prática, vejamos algumas iniciativas que se manifestam nessa direção: a edição de janeiro 
Reafirmo que, mesmo com essas posições, entendo que é preciso publicar e primar pela qualidade, fomentar a pesquisa e a produção do conhecimento científico, mas ao mesmo tempo em que possamos construir mecanismos que permitam pontes mais sólidas entre os trabalhadores do campo da EF e sua produção, em que eles também possam perceber-se como sujeitos que podem produzir, constituindo-se, por exemplo, como autores da docência. Exemplo interessante disso é a proposta dos Cadernos de Formação RBCE, lançado no Conbrace 2009, em Salvador, que visa especificamente constituir-se como uma produção de "inspiração" didático-pedagógica para professores e professoras que atuam no âmbito da EF escolar.

Finalizando este apontamento, considero que enfrentar os abismos existentes referentes às ainda mal resolvidas relações entre teoria e prática trata-se de uma pauta que deve constar na agenda de uma sociedade científica tal como o CBCE.

\section{SEGUNDO APONTAMENTO - RESPONSABILIDADES E POSSIBILIDADES PARA AS SECRETARIAS ESTADUAIS...}

Outra frente de discussão que precisa ser tencionada se apresenta a partir dos trabalhos desenvolvidos pelas secretarias estaduais e, por consequência, pelos associados do CBCE. Venho entendendo como interessante a ideia de interiorizar geograficamente as secretarias em cada estado onde elas se estabelecem, no sentido de possibilitar uma maior organicidade do CBCE em diferentes contextos de diferentes regiões de nosso país. Vejamos.

Segundo dados do próprio CBCE (2009), no ano de 2008, I.046 associados fizeram parte do CBCE nesse período. Considerando que, em anos de Conbrace, o número de associados aumenta, é possível inferir que houve certo incremento nesse número para o exercício de 2009. Destes 1.046 associados, 57,87\% são

de 2007 da RBCE teve como temática central "Didática, educação física/ciências do esporte"; o tema central do IV Congresso Sul Brasileiro de Ciências do Esporte, realizado em Faxinal do Céu (PR), em 2008, foi "Ciência e experiência"; o tema central da IX Semana Acadêmica da EF na UFSC, realizado em Florianópolis (SC) em 2008, foi "Concepção e intervenção"; o tema central da edição n. 28 da Revista Motrivivência foi "Relações entre conhecimento e prática pedagógica no campo da EF"; e o tema central do XVI Conbrace/III Conice (2009) foi "Formação em educação física e ciências do esporte: políticas e cotidiano", entre outros fóruns e publicações que procuram estabelecer pontes entre produção acadêmica e intervenção. Apesar disso, a interlocução mais concreta entre a produção e os processos de intervenção no campo da EF ainda são difíceis (talvez devido à aparente ampliação da carga de trabalho dos trabalhadores do campo tanto no âmbito das universidades, como nos espaços de intervenção escolares e não escolares). 
oriundos de apenas cinco secretarias ${ }^{4}$. Diante do grande número de professores de EF do Brasil (somente em Chapecó, estima-se que há em torno de 350 professores de EF) e do grande número de cursos de EF nas universidades brasileiras 5 , I.046 associados trata-se de um número bastante tímido.

Nessa direção, uma responsabilidade importante compete às secretarias estaduais. Proposta nesse sentido foi desenvolvida pela gestão 2008-2009 da Secretaria Estadual de Santa Catarina, na qual exerci a função de secretário adjunto. A secretaria foi composta por um coletivo que se apresentou com uma proposta de interiorização do CBCE no estado de Santa Catarina. A chapa intitulada Ampliando o Movimento - Do Centro À Periferia..., composta por um coletivo de sete professores ${ }^{6}$, oriundos de cinco cidades-sede (Chapecó, Lages, Criciúma, Florianópolis e São Miguel do Oeste), se constituiu nessa direção.

Essa experiência permitiu continuar com a sede de Florianópolis, composta basicamente por professores e estudantes do Centro de Desportos da Universidade Federal de Santa Catarina, alguns já com larga experiência de gestões anteriores diante da secretaria, mas também, ampliar as inserções do CBCE no estado, estabelecendo mais quatro cidades-sede, onde diversas ações puderam ser desenvolvidas pelo coletivo da secretaria.

Essa proposta vem sendo bastante enaltecida em diferentes fóruns de discussão, o que legitima uma perspectiva de ampliar o movimento do CBCE a partir de um processo de interiorização. A nova chapa eleita para o biênio 2009-20 I I se apresenta, em tese, na condição de dar continuidade a essa proposta, a partir de um novo coletivo composto por oito professores ${ }^{7}$, oriundos de cinco cidades-sede: Itajaí, Chapecó, Concórdia, Itajaí e Criciúma.

Entendo que o CBCE ainda se apresenta como um norte (ou sul, como diria Paulo Freire) significativo para sujeitos vinculados ao campo da educação física/ciências

4. Nomeadamente, 22,18\% oriundos da Secretaria Estadual do Paraná, 9,66\% de Goiás, 9,08\% do Rio Grande do Sul, 8,54\% de São Paulo e 8,41\% de Santa Catarina.

5. Dados do Instituto Nacional de Estudos e Pesquisas Educacionais Anísio Teixeira (Inep) apresentam informações de que, em 2004, havia 469 cursos de EF nas instituições de ensino superior brasileiras (HUNGER et al., 2006). É possível inferir que esse número deve ter aumentado nesses últimos seis anos.

6. Compondo a chapa: Ricardo Rezer (Unochapecó/Chapecó), Oliveira Fernandes Júnior (Uniplac) Lages), Mara Rossi (Uniplac/Lages). Compondo o grupo de colaboradores diretos: Vidalcir Ortigara (Unesc/Criciúma), Marlini Lima (Unochapecó/Chapecó), Elisa Abrão (UFSC/Florianópolis), Marcos Vieira (Unoesc/São Miguel do Oeste).

7. Compondo a chapa: Bruno E. Santana da Silva (Univali/ltajaí), Vanessa Marocco (Unochapecó/ Chapecó), Alexandre Vanzuita (Uniplac/Lages). Compondo o grupo de colaboradores diretos: Neusa Kleinubing (Unochapecó/Chapecó), Marizete Matiello (Unochapecó/Chapecó), Anelise F. Lunge (UNC/Concórdia), Santiago Pich (Univali/Itajaí), Vidalcir Ortigara (Unesc/Criciúma). 
do esporte, que trabalham, estudam, pesquisam, enfim, que lutam por mudanças em uma estrutura social que se manifesta aquém das necessidades humanas. Nesse sentido, redes de comunicação com um leque ampliado podem-se constituir como uma possibilidade de potencializar ações desenvolvidas, bem como estar mais perto dos diferentes atores em diferentes cenários.

Nesse caso, as responsabilidades das secretarias estaduais se apresentam na direção de permitir essa organicidade, possibilitando a abertura de canais de comunicação consistentes entre os associados e as instâncias diretivas em cada estado.

Não pretendo com essa argumentação idealizar esta "forma-de-ser" que as secretarias podem assumir, pois diversos problemas também fazem parte dessa proposta. Por exemplo, as dificuldades de articular colegas de diferentes cidades, onde a distância entre o coletivo da secretaria é um problema e reuniões por e-mail, Skype e MSN são interessantes, mas não são como um contato pessoal, dialogado, fluído de acordo com a interação calorosa de seres humanos que se encontram com predisposição ao diálogo. Porém entendo que essa proposta apresenta ricas possibilidades, não obstante, precisa de maior tempo e amadurecimento, no sentido de percebermos até onde é possível avançar nessa perspectiva.

Outro elemento importante nesta discussão é que, ao que parece, há uma retração no envolvimento político de significativo número de associados ${ }^{8}$. Por um lado, isso revela que há uma desarticulação política com muitas instâncias de base, o que pode representar um descuido da própria sociedade científica e das próprias secretarias. Em tempos de internacionalização, como apontam as ações das duas últimas gestões da direção nacional, entendo que o CBCE tende a olhar para fora de seus contornos geográficos. Entretanto não pode, absolutamente, esquecer das bases que o constituiu ao longo de sua própria história.

O quanto essas questões vêm-nos interessando, enquanto coletivo organizado em uma sociedade científica, trata-se de uma questão pertinente nestes tempos complexos no qual vivemos.

8. Por exemplo, as dificuldades para constituir uma chapa para assumir as instâncias diretivas do CBCE, tanto no que se refere à Direção Nacional como em diversas secretarias, é um indicativo bastante significativo dessa inferência. Outro exemplo para ilustrar essa retração, mesmo com votação em urna eletrônica, apenas 3 I 5 associados votaram na chapa eleita para a Direção Nacional referente ao biênio 20 I 0-20 I I. Isso representa, considerando dados do exercício de 2008, pouco mais de 30\% de votantes (Disponível em: <www.cbce.org.br>. Acesso em: 25 ago. 2009). Em Santa Catarina, mesmo com os esforços de interiorização promovidos, apenas 22 associados participaram do processo eleitoral em 2009. Penso que são números tímidos que merecem um olhar mais apurado dessa nova gestão que assume essa responsabilidade. 
É possível iniciar esse apontamento a partir de um exemplo hipotético: na contemporaneidade do campo da EF, um pesquisador que se debruça sobre, por exemplo, o treinamento esportivo, em certa medida, pode "desconsiderar" a produção epistemológica do campo e, provavelmente, o inverso também seja muito comum. É como se esses pesquisadores, em cada subcampo específico, tratassem de diferentes "educações físicas" (ver mais em REZER, 2009), constituindo suas pesquisas ou práticas de intervenção, independentes umas das outras.

Trazendo esta discussão para o âmbito dos Grupos de Trabalho Temático (GTTs) do CBCE, eles se constituem, em certa medida, com um grau de autonomia que, se assim o desejar, podem desconsiderar as produções e "formas-deser" de outros GTTs, "especializando" cada vez mais a discussão interna de cada grupo. Como exemplo, as decisões editoriais dos GTTs sobre os textos enviados ao Conbrace/Conice são determinadas com "total autonomia", como consta em comunicado da Direção Nacional datado de 3 I de julho de 2009 .

Penso que esta se trata de outra questão de difícil encaminhamento. Por um lado, a configuração dos GTTs se torna interessante, pois permite que diferentes subcampos possam articular-se de acordo com seus "tempos" próprios. Por outro, pode fragmentar a discussão de campo como um todo, pois permite que os GTTs estabeleçam "muros" que, por vezes, são difíceis de serem derrubados. Em tese, acabam configurando comunidades invisíveis (muito próximas dos argumentos já referidos por KuHN, 2006), que se constituem por acordos próprios de comunicação, que se apresentam a partir de acordos de linguagem, que representam certa singularidade entre eles, desconsiderando muitas vezes, por exemplo, a própria ementa do GTT. Assim, esses acordos permitem níveis de interlocução que, a priori, já têm determinadas demarcações políticas, éticas e epistemológicas esperadas.

Os encontros em assembleias, mesas temáticas, com diferentes posições assumidas por pesquisadores de diferentes "origens", oficinas e seminários introdutórios e/ou de aprofundamento, são estratégias que diferentes direções nacionais vêm estabelecendo, demonstrando que, se não houver um cuidado, as diferenças entre diferentes "educações físicas" pode constituir-se como mais um empecilho

9. Considero que, pela importância no próprio processo de constituição do CBCE, os GTTs se apresentam de forma muito importante nesse contexto, mas não podem correr o risco de se tornarem mais autônomos que a própria sociedade que os abriga. 
estruturante para as pretensões do CBCE. A própria estruturação do Pré-Conbrace realizado em Florianópolis (2009), em certa medida, contribui com essa pretensão de diversidade, visto que os trabalhos apresentados não se restringiram aos muros dos GTTs. Lembrando o capítulo IV, artigo 8 ${ }^{\circ}$ do Regimento dos GTTs, está prevista, como atribuição para cada GTT, a necessidade de "estabelecer intercâmbio científico com outros GTTs" (Fonte: <www.cbce.org.br>).

Interessante esforço nessa direção foi proposto no último Conbrace, em Salvador, 2009, no qual ocorreu uma Programação Conjunta entre os GTTs Políticas Públicas, Formação Profissional e Escola, em uma mesa que abordou o tema "Formação profissional e políticas educacionais". Foi uma experiência interessante, que precisa de novos esforços, na perspectiva de ampliar as aproximações entre conhecimentos que possuem diversos pontos de aproximação entre si.

Entendo a complexidade dessa questão, visto, por um lado, as necessidades metodológicas que se apresentam para estruturar um coletivo como o CBCE. Entretanto, considero pertinente promover essa reflexão, na medida em que este texto se apresenta no sentido de promover pontes entre perspectivas que, se por um lado são diferentes, por outro transitam em um mesmo âmbito, o que merece maior atenção dessa comunidade. Se há diferentes perspectivas para a EF brasileira, que não conseguem discutir entre si, é preciso construir então solos comuns, que podem permitir edificar novos argumentos acerca de fenômenos que não podem isolar-se em fragmentos, em um momento histórico que aponta para a necessidade de estabelecer conexões entre diferentes campos do conhecimento, como abordado anteriormente.

\section{QUARTO APONTAMENTO - CONSTRUINDO UM "SOLO COMUM": O CBCE COMO CAMPO DE POSSIBILIDADES DE DIÁLOGO...}

Com base nos apontamentos desenvolvidos anteriormente, parto da ideia de que se faz necessário investir em possibilidades de diálogo para a EF em cenário acadêmico - científico, tal como o CBCE, sem incorrer no erro de romantizar esse processo. Do contrário, o que esperamos? Uma ruptura definitiva entre diferentes "educações físicas"? Um "discurso vencedor"? Ou um "final feliz e viveram juntos para sempre"? Não acredito como possíveis essas pretensões e as compreendo como ingênuas, fragmentadas e/ou insuficientes. Afirmo isso porque outros campos do conhecimento e, por consequência, outras comunidades cientíicas também se encontram em ebulição (campos do conhecimento como a física, a química e a história também se encontram em um momento efervescente em suas discussões internas). 
Assim, entendo não ser possível pensar em um consenso para o campo, mas sim entendo como possível pensar em percepções arrazoadas (pelos critérios de cientificidade ou não), que fazem sentido para aqueles que direta ou tangencialmente operam nele. Partindo desse pressuposto, não existe um ponto arquimediano, em que algum ser ou campo "iluminado" possa proferir a palavra definitiva. Assim, precisaremos aprender a superar o pensamento de que há a necessidade de um "discurso vencedor", pois, lembrando Gadamer (2002), nenhum de nós (portanto, nenhum campo ou subcampo) abarca a verdade "em si".

Porém, entendendo que há diferentes pressupostos que se "cruzam" no âmbito do CBCE, é possível dialogar com Palmer (2006), quando ele afirma que precisamos de pressupostos. Mas de onde vêm os pressupostos que sustentam diferentes posições político-epistemológicas? Da tradição em que nos inserimos, que se constitui como um horizonte no interior do qual pensamos. Assim, "a tradição fornece um fluxo de concepções no interior do qual nos situamos e devemos estar preparados para distinguir entre pressupostos que dão fruto e outros que nos aprisionam e nos impedem de pensar e ver" (p. 187). Possivelmente, Hannah Arendt (2007) chamaria isso de discernimento.

Dessa forma, se não pode haver uma interpretação sem pressupostos, a noção de interpretação correta enquanto correta "em si" é um ideal impensável e trata-se, então, de uma impossibilidade. Por isso, desdobrando o pensamento de Palmer (2006) para este texto, uma sociedade científica como o CBCE tem que ser compreendida na situação hermenêutica em que se encontra. Porém isso não quer dizer que o assunto está resolvido e cada um pode continuar com seu próprio mundo, sua própria compreensão, pois vivemos em um mesmo mundo. Pelo contrário, essa posição assumida reconhece que o significado não é uma propriedade imutável de "algo", pois o significado deste "algo" é sempre um "para nós", surgido da situação hermenêutica. Essa postura permite considerar a impossibilidade de defender a ideia de uma verdade em si mesma ou de uma interpretação eternamente correta. Isso permite considerar também a incompletude dos diferentes campos que direta ou indiretamente operam relações com o campo da EF no interior do CBCE, bem como implica afirmar a necessidade de maior interlocução entre eles, sob risco de assumirmos um paradigma sempre insuficiente (ou nos sobra, então, lidar com a diversidade pela truculência ${ }^{10}$ ).

10. Lembro uma discussão em meio à Assembleia do CBCE datada de 24 de setembro de 2009, no último Conbrace/Conice. Diante de um encaminhamento da mesa diretiva, uma professora pediu a palavra, intervindo por meio de "questão de ordem", confrontando o encaminhamento assumido pela mesa. Ao ter negada sua solicitação, que não vem ao caso resgatar, ela afirmou categoricamente: 
Esse pensamento aqui assumido se apresenta de maneira diferente do desenvolvimento do pensamento moderno, principalmente na postura austera de considerar o "outro" alguém com possibilidades de também, a seu modo, "estar certo".

Penso que uma responsabilidade importante para uma sociedade científica é possibilitar uma ampliação na capacidade de "olhar" para o mundo, nesse caso, pela janela da EF/CE. Isso permite tratar a relação entre diferentes paradigmas como uma relação entre horizontes distintos, e a fusão entre eles, conforme Gadamer (2002), permite considerar novas e ampliadas perspectivas, para lidar com novos horizontes que por consequência se abrem. Nessa relação, os sujeitos não se separam, mas mergulham em uma relação que "joga" com as possibilidades estabelecidas entre eles, em um movimento dinâmico e dialético.

Dessa forma, concordando com Berticelli (2004), se a busca de conhecimento é sempre uma busca de sentidos (e a ciência, bem como a constituição de qualquer comunidade que se aproxime dela, é sempre um processo de produção de sentidos), torna-se pertinente uma abordagem que chame a atenção do processo hermenêutico em que o CBCE se encontra, em um desafio interpretativo de compreender melhor os sentidos construídos nas relações entre os protagonistas desse coletivo. Isso permite construir variadas possibilidades interpretativas de acordo com o "olhar" dispensado, o que, por consequência, leva a diversas novas perguntas, que se apresentam em um movimento dialógico intenso na dinâmica da pergunta e da resposta. De acordo com Gadamer (2002), talvez seja imperioso neste momento aprendermos, de forma mais atenta, a ver perguntas onde parecem existir pretensiosas respostas peremptórias:

Ver perguntas significa, porém, poder romper com uma camada, como que fechada e impenetrável, de preconceitos herdados, que dominam todo nosso pensamento e conhecimento. $\bigcirc$ que perfaz a essência do investigador é a capacidade de ruptura que possibilita ver, assim, novas perguntas e encontrar novas respostas (p. 67).

Muitas vezes, boas perguntas são mais importantes que as próprias respostas. Segundo Gadamer (idem), o perguntar pode ser entendido como um horizonte, pois a partir do perguntar se determina o ponto de partida que determina a orientação do sentido de algo. Ou seja, o que se busca compreender é sempre o orientador daquilo que pode ser compreendido. Nessa direção, Gadamer afirma que um

"Vocês não podem pensar assim, vocês tem que pensar deste jeito" (no caso, do "jeito" dela). Penso que discussões assim não levam a lugar algum, visto a impossibilidade de diálogo, em que, em casos como estes, as partes não querem discutir, mas sim "ter razão". 
horizonte não é uma fronteira rígida, senão algo que se desloca conosco e que convida a seguir adentrando nele.

Entendo o CBCE como um cenário de contornos movediços, que tem entre suas responsabilidades a perspectiva de ampliar os horizontes de diferentes "educações físicas", que se aproximam desse possível solo comum. A preocupação aqui se apresenta no sentido de construir pontes, em que a discussão se desenvolva em direção a um desdobramento nas relações entre os sujeitos que convergem, nesse caso, em um contexto para "falar sobre" EF e suas relações com o mundo, a partir de diferentes perspectivas.

A importância, então, de aproximar esta discussão da hermenêutica se apresenta a partir da possibilidade de construir, lembrando Ricoeur (2008), uma explicitação de um solo ontológico, que me venho referindo neste texto como "solo comum", sobre o qual essas diferentes comunidades possam edificar-se. Dessa forma, a proposição aqui estabelecida não sugere um processo de amálgama entre diferentes posições político-epistemológicas de campos e subcampos da EF brasileira, mas sim um espaço de discussão e diálogo entre diferentes filosofias, pensando o CBCE como um possível solo comum, que permitiria a edificação do próprio campo, derivado desse processo comunicativo. Talvez aí esteja, pelo menos no plano teórico, em aberto, uma possibilidade comunicativa para o interior do campo.

Entendo que esse processo comunicativo pode ocorrer, de forma paulatina, derivado dos entendimentos e das disputas dos diferentes agentes do campo, mas essa constituição não pode derivar-se do projeto de apenas um dos setores implicados nesse âmbito, ou do consenso pacífico entre estes, mas sim fruto de uma trajetória, ou seja, de um campo constituído dos conflitos, de lutas e embates entre seus protagonistas.

Nesse caminho, a fusão de horizontes expressa por Gadamer (2002) pode-se apresentar como uma possibilidade interessante para lidar com essa complexidade. Nesse sentido, considero a intervenção pedagógica no campo da EF como uma possibilidade, senão uma grande possibilidade, de fusão de horizontes, de marcar as diferenças e construir possíveis aproximações. Visualizo, então, na sua dimensão pedagógica, uma possibilidade comum para o campo da EF em um cenário como o CBCE, lembrando Palmer (2006), quando ele afirma que na fusão de horizontes, que é o ponto fulcral da experiência hermenêutica, há elementos do nosso horizonte que recuam e outros que avançam, porém se movimentam em um diálogo constante, comunicativo na origem e respeitoso por princípio.

Se isso é possível, o tempo irá dizer. Mas, sem dúvida, precisamos de esforços contínuos na direção de lidar com a complexidade dos paradoxos e contradições estabelecidas nas relações internas de uma sociedade científica tal como o CBCE. 
Na perspectiva aqui apresentada, a discussão proposta pode-se apresentar como nobre tarefa para os sujeitos que constituem o CBCE. Penso que esse cenário se encontra na condição de uma "zona de fronteiras", e portanto perigosa, como bem sabem os povos fronteiriços. Desse modo, o empenho em permitir que diferentes comunidades dialoguem em um solo comum, em um esforço de fusão de horizontes, e a capacidade de compreender a incompletude de qualquer abordagem e se sentir incomodado com pretensões de completude podem contribuir significativamente com uma convivência mais respeitosa entre as diferentes comunidades que operam no campo da EF brasileira.

Nesse caso, assumindo uma postura gadameriana, entendo que é necessário enfatizar o comum ao invés das diferenças, pois temos que aceitar que já percorremos um longo caminho juntos antes de marcar o estágio no qual devemos andar separados. Assim, entra a possibilidade de considerar um esforço hermenêutico no cenário da EF brasileira, que já há algum tempo tem sido empregada nas reflexões presentes no campo da EF (por exemplo, FENSTERSEIFER, 2007a, 2007b, 2009).

Levar a sério um referencial hermenêutico, inicialmente a partir de um processo de "olhar para dentro" das posturas assumidas no interior do CBCE, tanto no que se refere a relações políticas como a relações acadêmico-científicas, poderia proporcionar desdobramentos em diferentes espaços de intervenção do próprio campo, permitindo inclusive possibilidades para redimensionar a questão do próprio conhecimento produzido no campo da EF (nesse caso, mais especificamente, no âmbito do CBCE).

Espaços como o CBCE, diferentes de outras instituições (como, por exemplo, a Igreja e os partidos políticos), dever-se-iam reconhecer e se constituir como um espaço para pensar "sem teto" '।. O CBCE pode-se instituir como uma possibilidade ímpar para aproximar a divergência, tal como expresso em seu próprio estatuto, e não um espaço derivado do projeto de apenas um dos setores implicados nesse âmbito, pois sua construção (felizmente) se encontra em aberto.

Portanto, a possibilidade de tencionar a relação teoria e prática diante das responsabilidades do CBCE, bem como considerar as secretarias estaduais como um elemento fulcral na possibilidade de operacionalizar um processo de aproximação,

II. Lembro um exemplo apresentado pelo professor Paulo Evaldo Fensterseifer, quando afirma que o teto da Igreja seria o dogma da fé, inquestionável; os partidos políticos têm suas bases e convenções ideologicamente estabelecidas como verdade para esse âmbito, diferentes de âmbitos tais como o CBCE ou universidades, que não deveriam "ter teto". 
tanto geográfica como político-epistemológica, entre diferentes trabalhadores do campo, considerando a possibilidade de refletir acerca do papel dos GTTs nesta discussão, permite construir um pano de fundo que possibilite considerar fecunda a discussão sobre o CBCE constituir-se como um solo comum para os diálogos necessários que interessem a EF.

Isso se apresenta como uma possibilidade de construção de sentidos, considerando as limitações dos seres humanos, que, sem poder dizer inteiramente tudo que desejam, põem em jogo todo um conjunto de sentido. Dessa forma, visualizo, no diálogo possível, possibilidades vivas de construção de novos sentidos, em que um esforço hermenêutico pode permitir conviver melhor com diferentes possibilidades de compreender fenômenos relativos a EF/CE, entendendo a necessidade de constituir um solo comum, em que as diferentes comunidades constituídas nesse âmbito possam relacionar-se, mas não necessariamente precise emergir dessas relações um "discurso vencedor". Portanto, em tempos em que cruzar os braços parece não ser a melhor saída, sem cair no risco da idealização, entendo o CBCE como um palco privilegiado para essa investida.

The CBCE as "solo comum" for dialogue needed to field of physical education: four notes introductory...

ABSTRACT: This article aims to discuss the central role of the Brazilian College of Sport Science (CBCE). In order to do so, first of all we present a ransom of prospects fund that built the $C B C E$, and in a second time, we take notes on four issues related to the environment of the CBCE. Finally, at the fourth argument, I present some opinions on the important communicative possibilities for a scenario like the CBCE, thinking it as a "common ground" for different communities, which are related directly or tangentially to the field of EF. KEY WORDS: CBCE; common ground; physical education.

\section{El CBCE as "solo comum" para el diálogos necesarios para ámbito de la educación física: cuatro notas introductorias...}

RESUMEN: Este artículo tiene por objeto cuestionar el papel central del Colegio Brasileño de Ciencias del Deporte (CBCE). Para ello, inicialmente la presentación de un rescate de las perspectivas de fondo que construyó el CBCE para en un segundo tiempo, tomar notas en cuatro cuestiones relacionadas con el medio ambiente del CBCE. Por último, presento algunas posiciones en las importantes posibilidades de comunicación para un escenario como el CBCE, pensando que como "terreno común" para las diferentes comunidades que se relacionan directa o tangencialmente con el campo de la EF. PALABRAS CLAVES: CBCE; solo común; educación física. 


\section{REFERÊNCIAS}

ARENDT, H. O que é política?. 7. ed. Rio de Janeiro: Bertrand Brasil, 2007.

ATLAN, H. Entre o cristal e a fumaça: ensaio sobre a organização do ser vivo. Rio de Janeiro: Jorge Zahar, 1992.

BERTICELLI, I. A. A origem normativa da prática educacional na linguagem. ljuí: Unijuí, 2004 .

BIANCHETTI, L. 30 anos do Colégio Brasileiro de Ciências do Esporte: os desafios para uma associação científica e os dilemas dos intelectuais institucionalizados. Revista Brasileira de Ciências do Esporte, Campinas, v. 30, n. 3, maio 2009.

BRACHT, V. 30 anos do CBCE: os desafios para uma associação científica. Revista Brasileira de Ciências do Esporte. Campinas, v. 30, n. 3, maio 2009.

CBCE. Estatuto. Disponível em: <http://www.cbce.org.br/br/cbce/estatuto.asp >. Acesso em: 2 ago. 2009.

\section{9.}

. CBCE em números. Relatório da Direção Nacional - Gestão 2008-2009. Goiânia,

FENSTERSEIFER, P. E. Giros epistemológicos: o giro hermenêutico. In: XV CONBRACE/II CONICE, XV CONGRESSO BRASILEIRO DE CIÊNCIAS DO ESPORTE, Recife, 2007a. Anais... Recife: s.ed., 2007. p. I-8.

Bases teóricas da educação física: uma perspectiva histórica-hermenêutica. In: PAREJA, I. D. U.; CHAVERRA FERNÁNDEZ, B. E. (Org.). Aproximaciones epistemológicas y pedagógicas a la educación física: un campo en construcción. Medellín: Funámbulos, 2007b. p. $35-44$.

Linguagem, hermenêutica e atividade epistemológica na educação física. Movimento, UFRGS, v. I5, p. 6.046, 2009.

FOUREZ, G. A construção das ciências: introdução à filosofia e à ética das ciências. São Paulo: Universidade Estadual Paulista, 1995.

GADAMER, H.-G. Verdade e método II - Complementos e índices. 2. ed. Petrópolis: Vozes, 2002.

HUNGER, D.; NASCIMENTO, J. V.; BARROS, M. V. G.; HALLAL, P. C. Educação física. In: HADDAD, A. E.; PIERANTONI, C. R.; RISTOFF, D.; XAVIER, I. M.; GIOLO, J; SILVA, L. B. (Org.). A trajetória dos cursos de graduação na área da saúde: 1991 a 2004. Brasília: Instituto Nacional de Estudos e Pesquisas Educacionais Anísio Teixeira, 2006. p. 87- 139.

KUHN, T. S. A estrutura das revoluções científicas. São Paulo: Perspectiva, 2006. 
MEDEIROS, F. E. O futebol de "seis" quadrados nas aulas de educação física: uma experiência de ensino com princípios didáticos da abordagem crítico-emancipatória. Revista Brasileira de Ciências do Esporte, Campinas, v. 28, n. 2, jan. 2007.

MORIN, E. Ciência com consciência. 9. ed. Rio de Janeiro: Bertrand Brasil, 2005.

PALMER, R. Hermenêutica. Lisboa: Edições 70, 2006.

PRIGOGINE, I. O fim das certezas. São Paulo: Unesp, 1996.

REZER, R. "Formas-de-ser" da educação física contemporânea - Duas teses (não) conclusivas... In: XVI CONGRESSO BRASILEIRO DE CIÊNCIAS DO ESPORTE, III CONGRESSO INTERNACIONAL DE CIÊNCIAS DO ESPORTE. Anais... Salvador, 2009.

RICOEUR, P. Hermenêuticas e ideologias. Petrópolis: Vozes, 2008.

Recebido: 20 out. 2009 Aprovado: 31 mar. 2010

Endereço para correspondência: Universidade Comunitária Regional de Chapecó. Rua Senador Atílio Fontana, 59I-E - Efapi Chapecó-SC CEP 89809-000 